Supporting Information

\title{
MXene-derived nanocomposites as earth-abundant efficient electrocatalyst for nitrogen reduction reaction under ambient conditions
}

\author{
Guoliang Zhao', Xin Wang ${ }^{1,2}$, Chen $\mathrm{Xu}^{1 *}$ \\ ${ }^{1}$ Institute of Materials, China Academy of Engineering Physics, Jiangyou City \\ 621908, Sichuan, China \\ ${ }^{2}$ Department of Physics, McGill University, 3600 University Street, Montreal, \\ Quebec H3A 2T8, Canada \\ *Corresponding authors: chenxuacademic@163.com
}




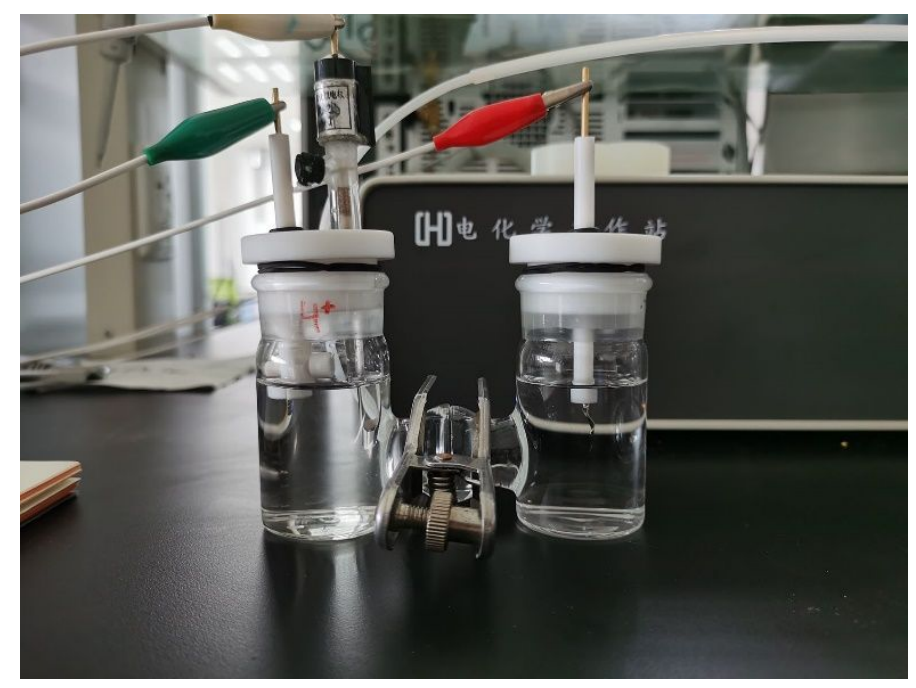

Figure S1. Photograph of H-type electrochemical cell. 


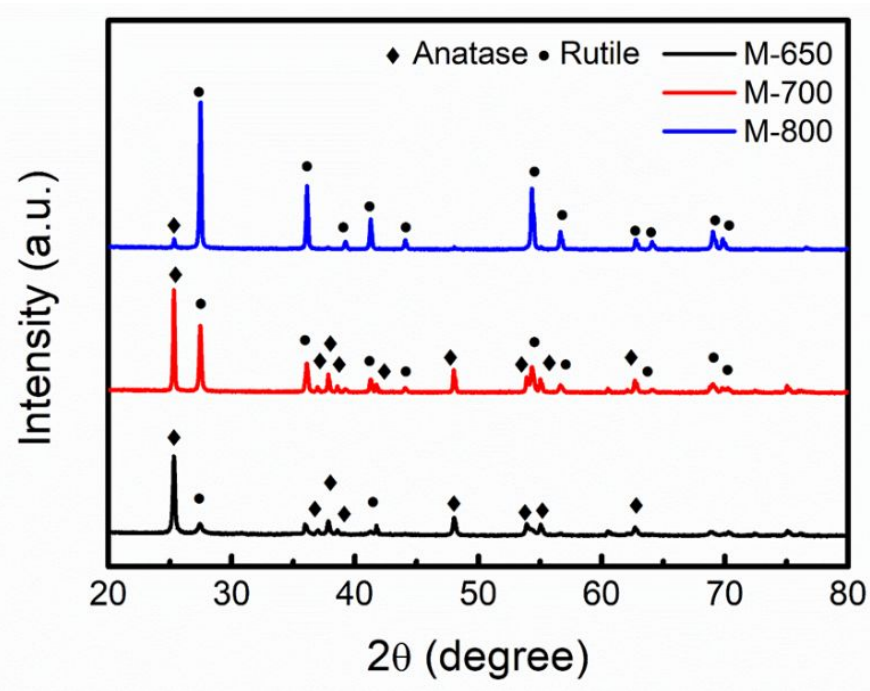

Figure S2. XRD patterns of M-650, M-700, and M-800.

Figure S2 shows the XRD patterns of M-650, M-700, and M-800. All the XRD patterns exhibit peaks corresponding to both anatase $\mathrm{TiO}_{2}$ and rutile $\mathrm{TiO}_{2}$. 


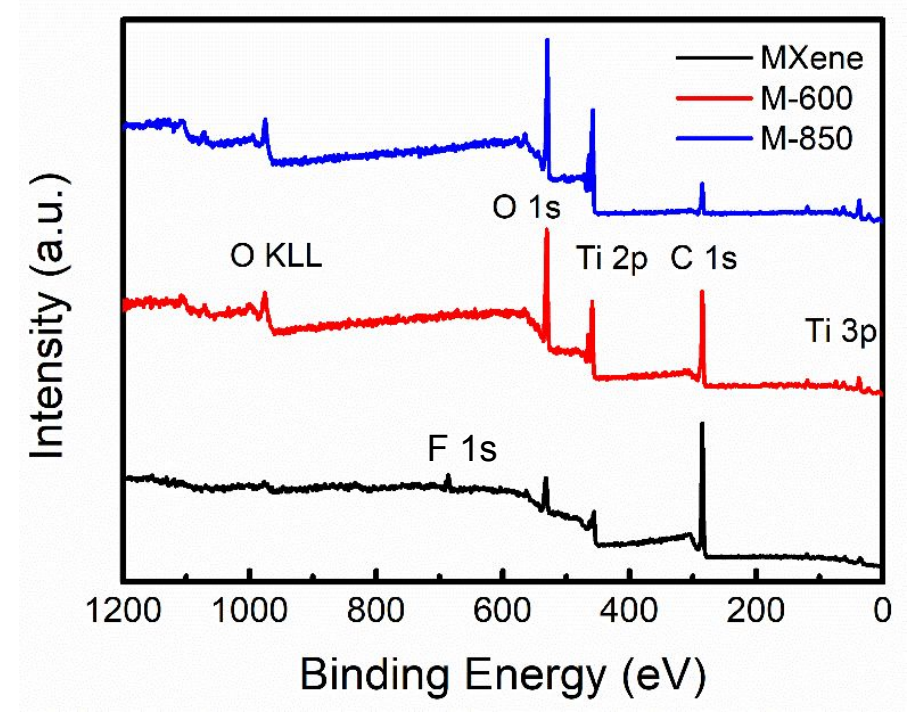

Figure S3. XPS survey spectra of MXene, M-600 and M-850.

Figure S3 shows the XPS survey spectra of MXene, M-600 and M-850. There are four main chemical elements $(\mathrm{C}, \mathrm{Ti}, \mathrm{F}$ and $\mathrm{O})$ on MXene, and the element of $\mathrm{F}$ disappear for sample M-600 and M-850. 


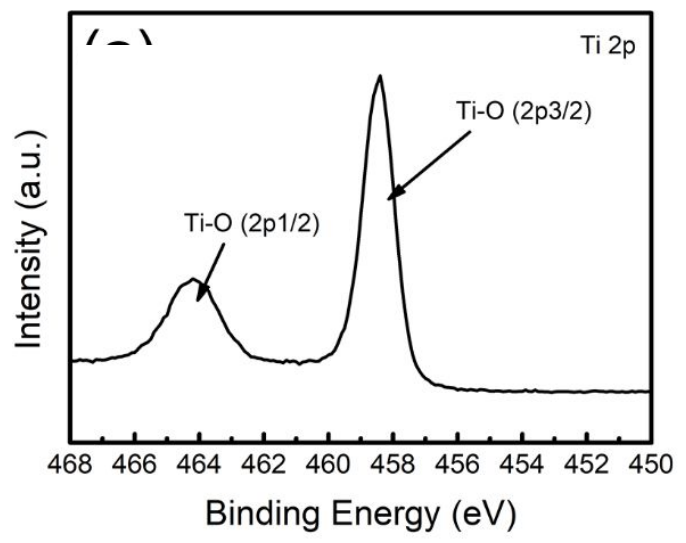

Figure S4. Ti 2p XPS spectra taken from sample M-850. 


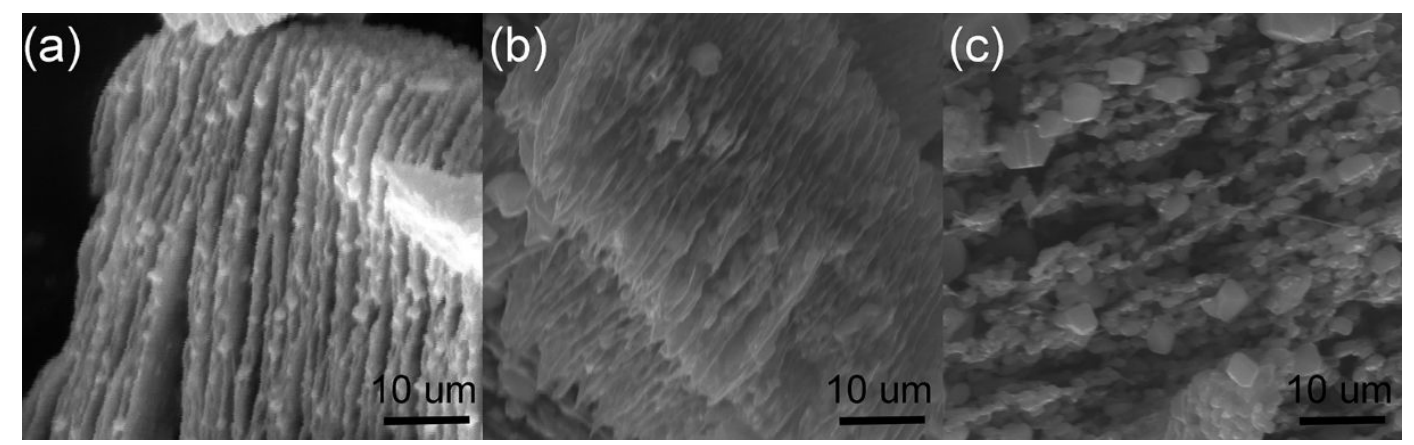

Figure S5. SEM images of the (a) M-650, (b) M-700 and (c) M-800.

Figure S5 shows the SEM images of the M-650, M-700 and M-800. It should be noted that size of the embedded $\mathrm{TiO}_{2}$ particles increases with raised annealing temperature. 

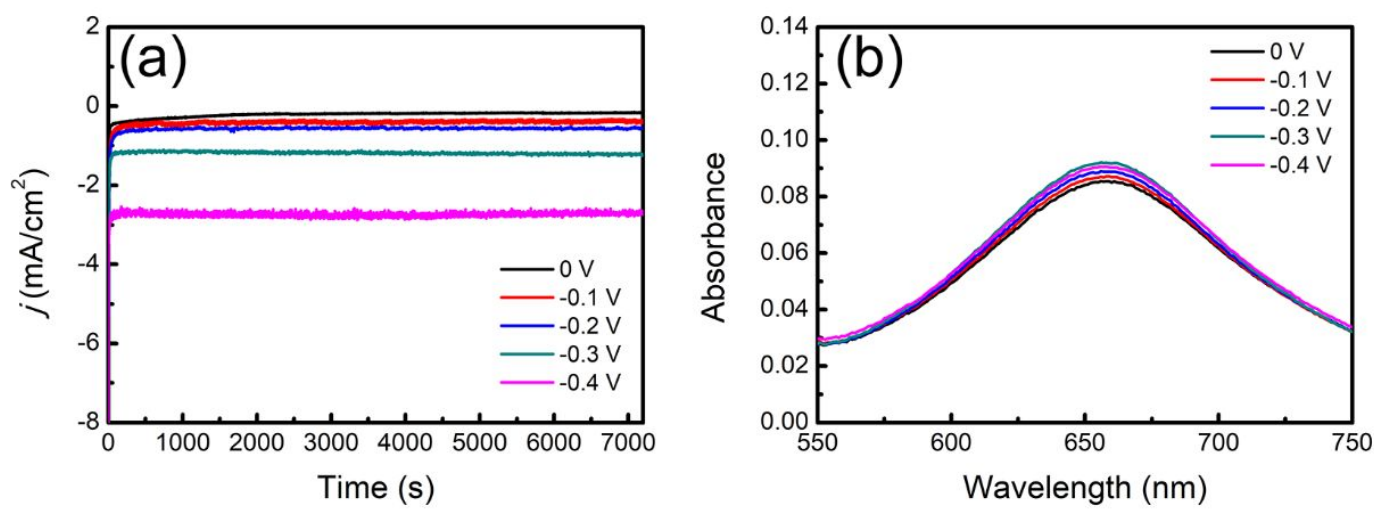

Figure S6. (a) Time-dependent current density curves for M-850 at different potentials in $\mathrm{N}_{2}-$ saturated $0.1 \mathrm{M} \mathrm{Na}_{2} \mathrm{SO}$. (b) UV-vis absorption spectra of the electrolytes coloured with an indophenol indicator after charging at different potentials for $2 \mathrm{~h}$. 

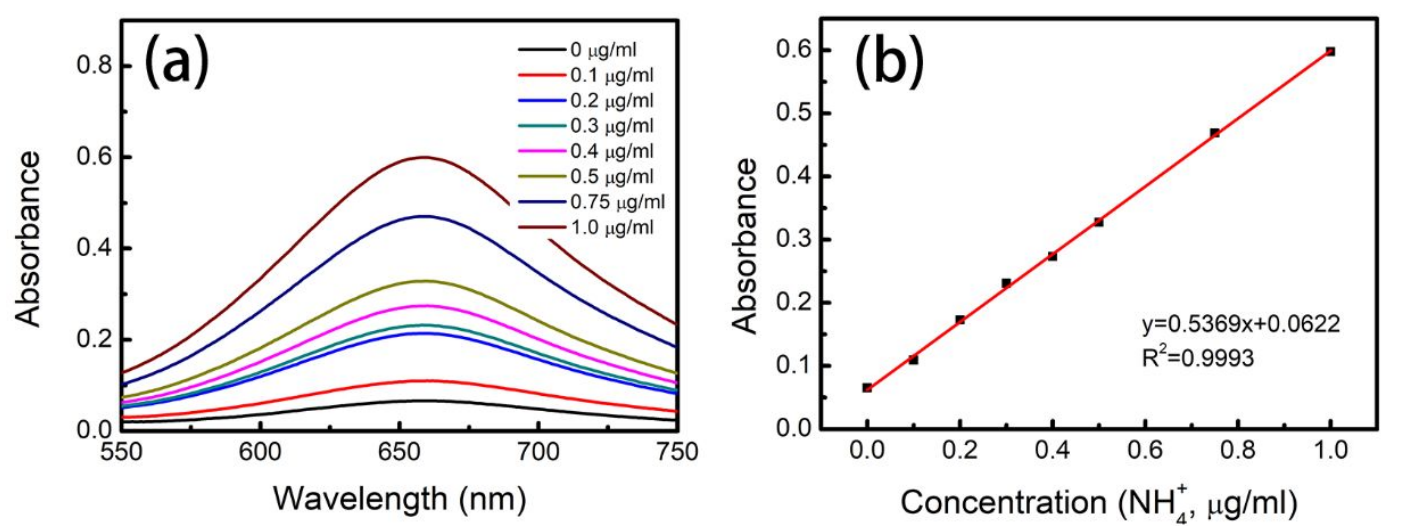

Figure S7. (a) UV-Vis absorption spectra of indophenol assays with $\mathrm{NH}^{4+}$ in $0.1 \mathrm{M} \mathrm{Na}_{2} \mathrm{SO}_{4}$ after incubated for $2 \mathrm{~h}$ at room temperature. (b) Calibration curve used for calculation of $\mathrm{NH}_{3}$ by $\mathrm{NH}^{4+}$ concentration. 


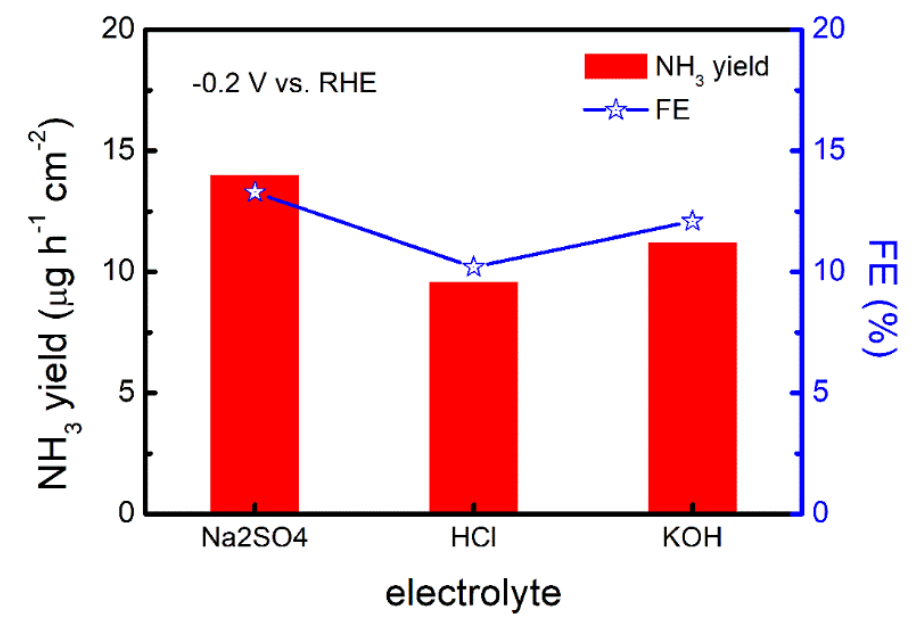

Figure S8. NRR activity of M-600 in different electrolytes.

\begin{tabular}{|c|c|c|}
\hline Electrolyte & $\mathrm{NH}_{3}$ yield $\left(\mu \mathrm{g} \mathrm{h}^{-1} \mathrm{~cm}^{-2}\right)$ & $\mathrm{FE} \mathrm{( \% )}$ \\
\hline $\mathrm{Na}_{2} \mathrm{SO}_{4}$ & 14.0 & 13.3 \\
\hline $\mathrm{HCl}$ & 9.6 & 10.2 \\
\hline $\mathrm{KOH}$ & 11.2 & 12.1 \\
\hline
\end{tabular}

We conducted NRR tests in $0.1 \mathrm{M} \mathrm{HCl}$ and $0.1 \mathrm{M} \mathrm{KOH}$, respectively. As shown in Figure $\mathrm{S} 8$, the $\mathrm{NH}_{3}$ yield can reach $9.6 \mu \mathrm{g} \mathrm{h}^{-1} \mathrm{~cm}^{-2}$. with a FE of $10.2 \%$ in $0.1 \mathrm{M} \mathrm{HCl}$, and $11.2 \mu \mathrm{g} \mathrm{h}^{-1} \mathrm{~cm}^{-2}$. with a $\mathrm{FE}$ of $12.1 \%$ in $0.1 \mathrm{M} \mathrm{KOH}$, respectively. $\mathrm{HCl}$ has a rich proton supply which might be beneficial to HER, so $\mathrm{NH}_{3}$ yield and $\mathrm{FE}$ both decreased. In addition, the NRR activity of M-600 in $\mathrm{KOH}$ is similar to that in $\mathrm{Na}_{2} \mathrm{SO}_{4}$. 


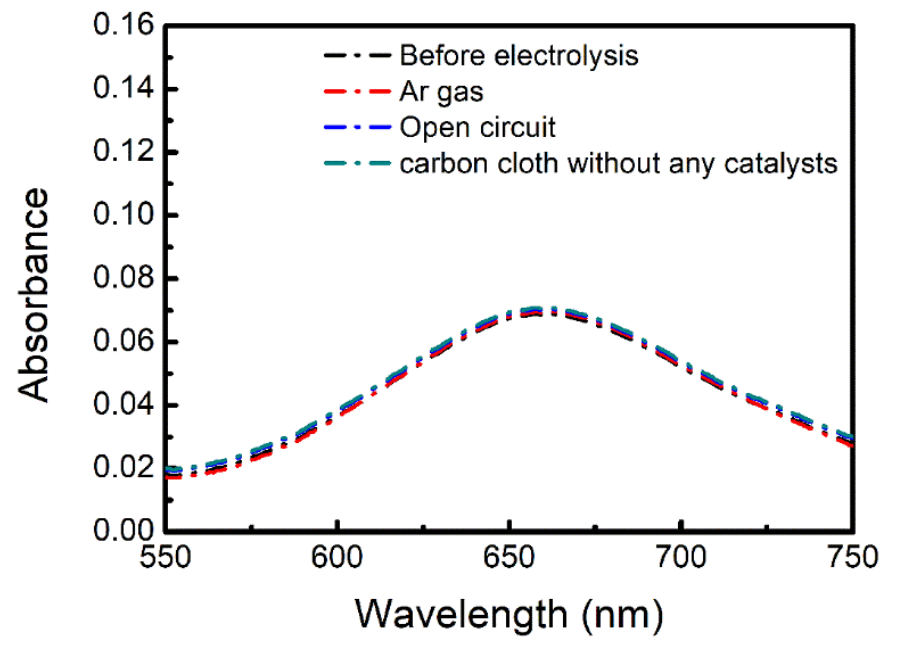

Figure S9. UV-Vis absorption spectra of electrolytes stained with indophenol indicator before and after $2 \mathrm{~h}$ electrolysis at the potential of $-0.20 \mathrm{~V}$ under different electrochemical conditions.

Figure S9 shows the UV-Vis absorption spectra of electrolytes stained with indophenol indicator before and after $2 \mathrm{~h}$ electrolysis at the potential of $-0.20 \mathrm{~V}$ under different electrochemical conditions. According to Figure S9, we can conclude that little $\mathrm{NH}_{3}$ is detected in both cases, which verifies that $\mathrm{NH}_{3}$ is produced by $\mathrm{N}_{2}$ reduction. 


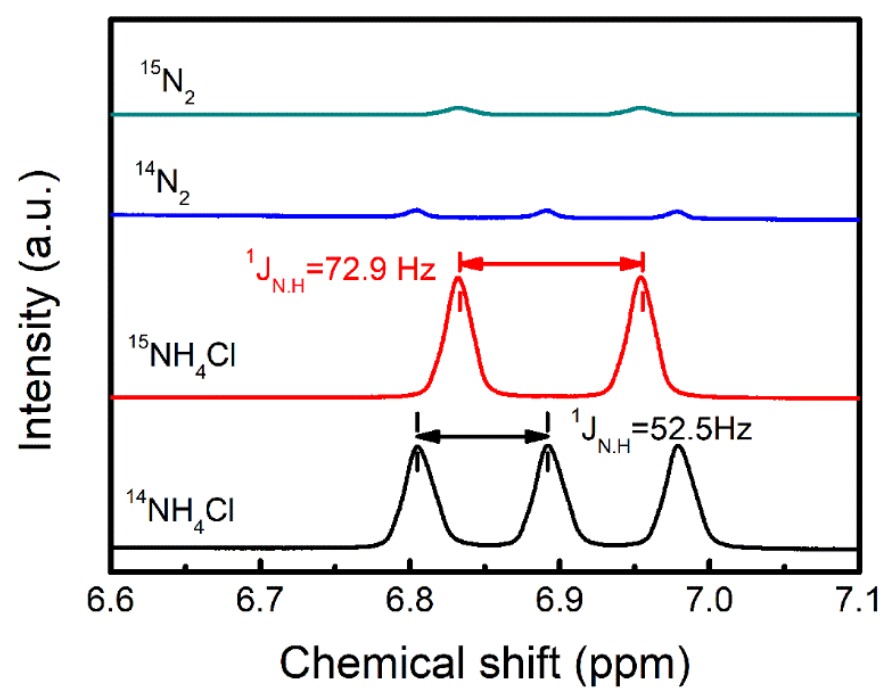

Figure S10. 1H NMR spectra of the electrolyte produced from the NRR tests using ${ }^{14} \mathrm{~N}_{2}$ and ${ }^{15} \mathrm{~N}_{2}$ as feeding gas. 

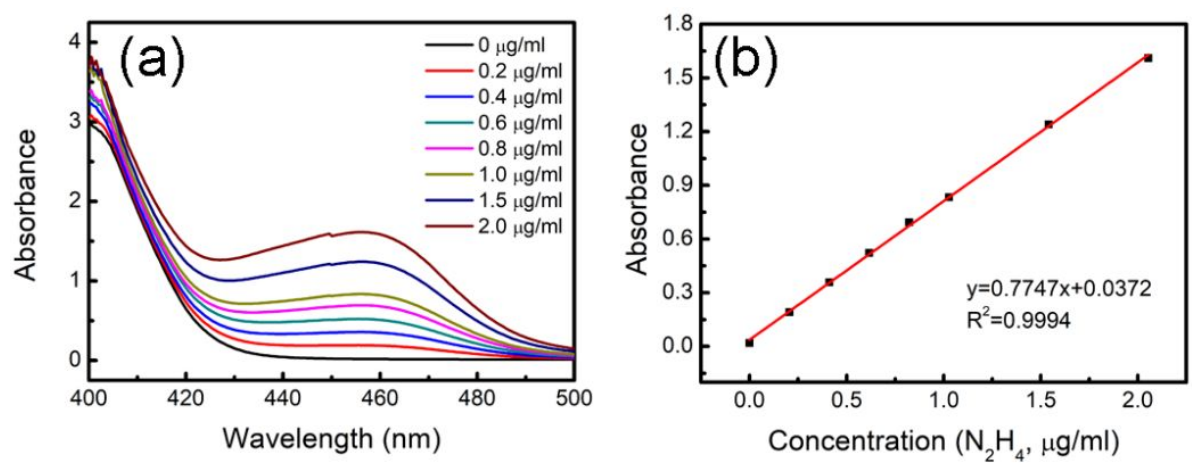

Figure S11. (a) UV-Vis absorption spectra of various $\mathrm{N}_{2} \mathrm{H}_{4}$ concentrations stained with $\mathrm{p}$ $\mathrm{C}_{9} \mathrm{H}_{11} \mathrm{NO}$ indicator after incubated for $10 \mathrm{~min}$ at room temperature. (b) Calibration curve used for calculation of $\mathrm{N}_{2} \mathrm{H}_{4}$ concentration. 


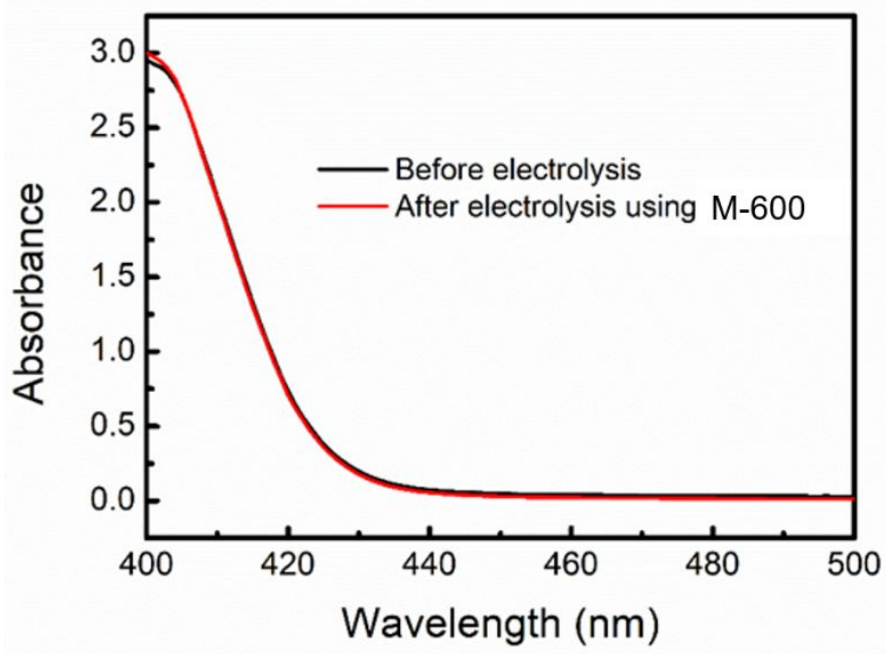

Figure S12. UV-Vis absorption spectra of the electrolytes estimated by the method of Watt and Chrisp before and after $2 \mathrm{~h}$ electrolysis in $\mathrm{N}_{2}$ atmosphere at $-0.20 \mathrm{~V}$.

Figure S12 shows the UV-Vis absorption spectra of the electrolytes estimated by the method of Watt and Chrisp before and after $2 \mathrm{~h}$ electrolysis in $\mathrm{N}_{2}$ atmosphere at $0.20 \mathrm{~V}$. The figure reveals that little $\mathrm{N}_{2} \mathrm{H}_{4}$ is produced during the NRR catalytic process, indicating that M-600 has excellent selectivity. 


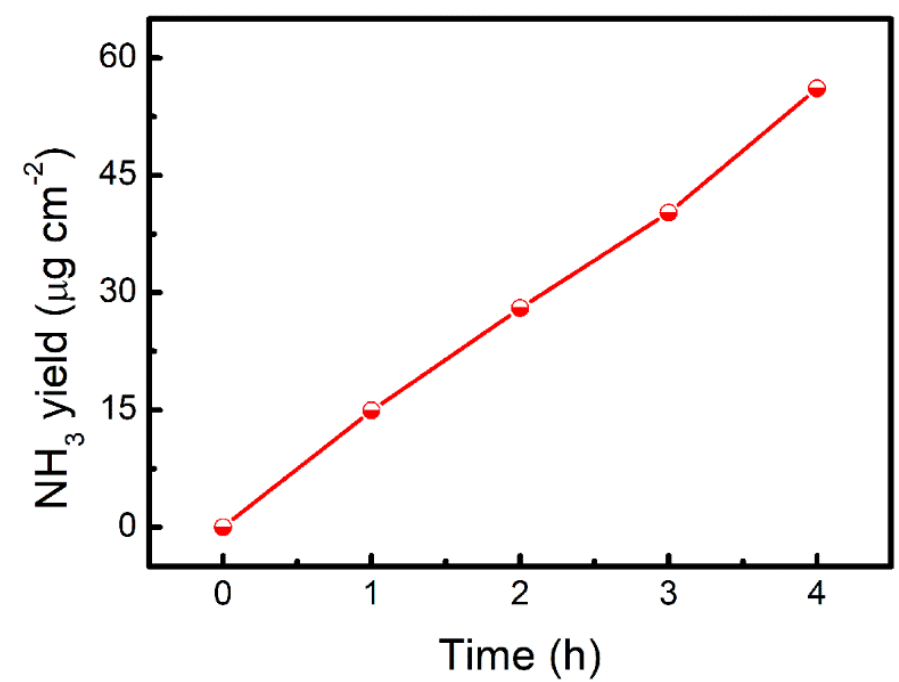

Figure $\mathrm{S} 13$. The $\mathrm{NH}_{3}$ yield of $\mathrm{M}-600$ vs. reaction time at $-0.2 \mathrm{~V}$. 


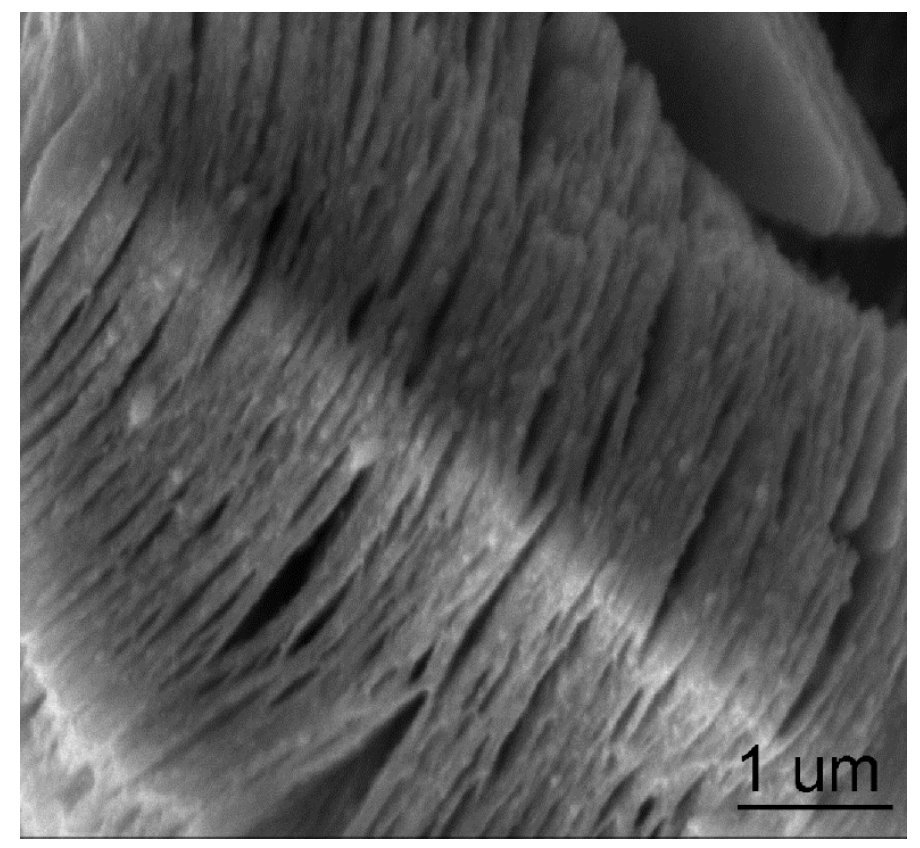

Figure S14. SEM image of M-600 after the stability test. 


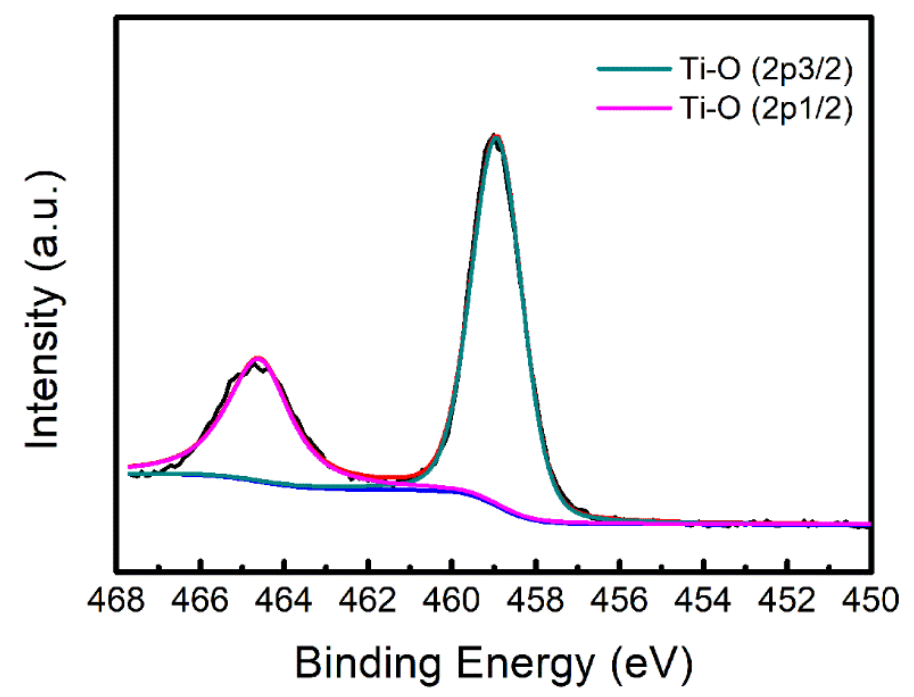

Figure S15. XPS spectra of Ti 2p of M-600 after the electrocatalytic test. 


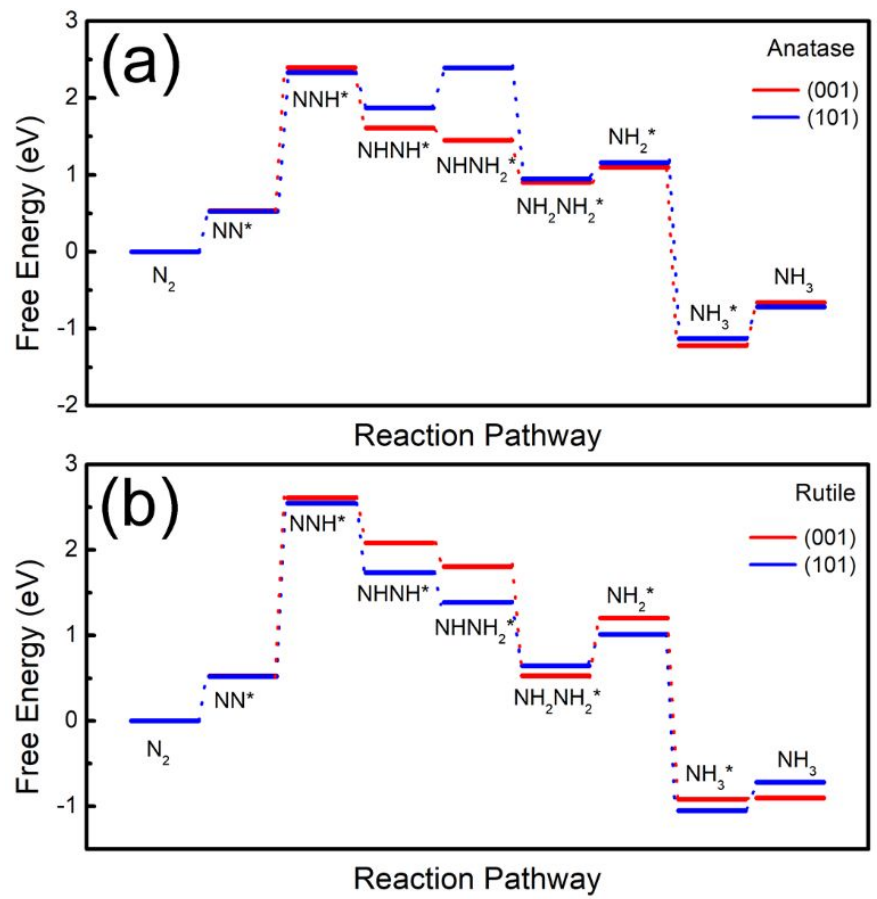

Figure S16. DFT calculated for the energetics of the NRR steps on the (001) and (101) facets of anatase $\mathrm{TiO}_{2}$ and rutile $\mathrm{TiO}_{2}$.

Figure S16 shows the DFT calculated for the energetics of the NRR steps on the (001) and (101) facets of anatase $\mathrm{TiO}_{2}$ and rutile $\mathrm{TiO}_{2}$. For both materials, the (101) facets show lower free energy than that of (001) facets, so the (101) facets are selected to build simulation models for further DFT calculations. 


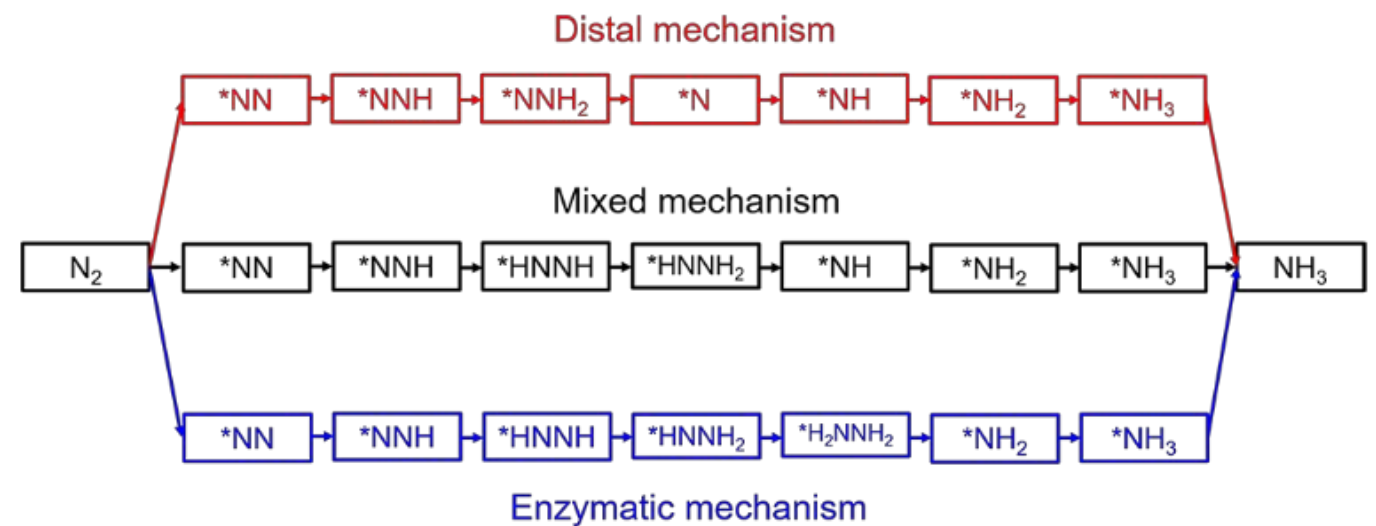

Figure S17. Schematic depiction and the relevant structures for the three mechanisms for $\mathrm{N}_{2}$ electroreduction to $\mathrm{NH}_{3}$. 

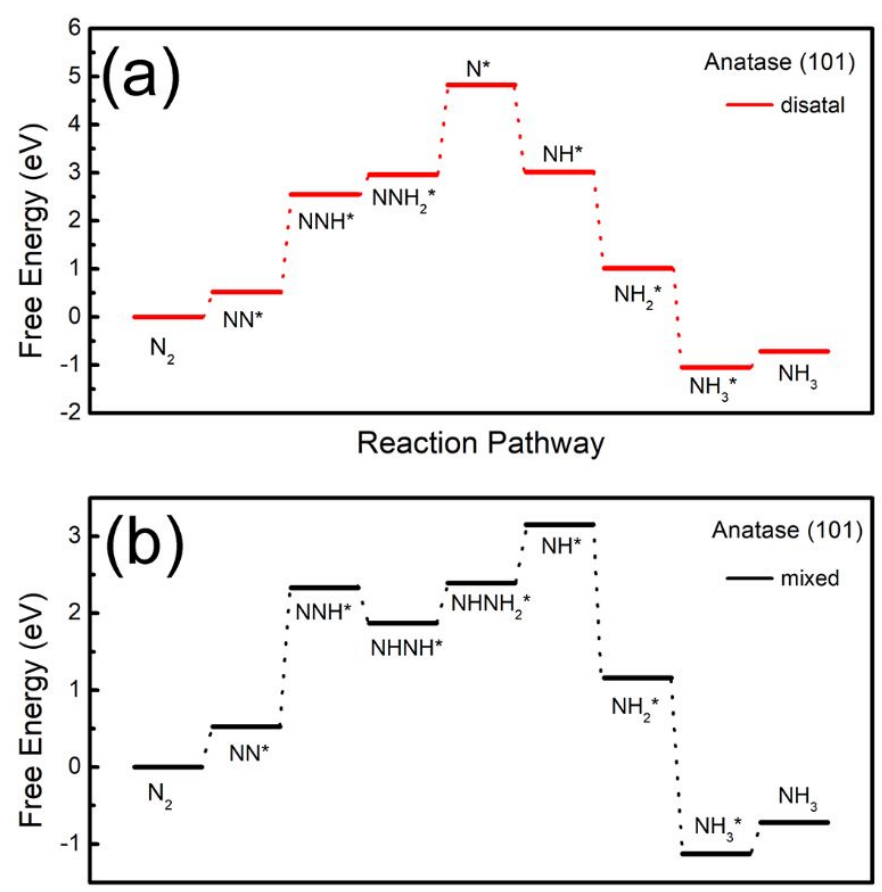

Reaction Pathway

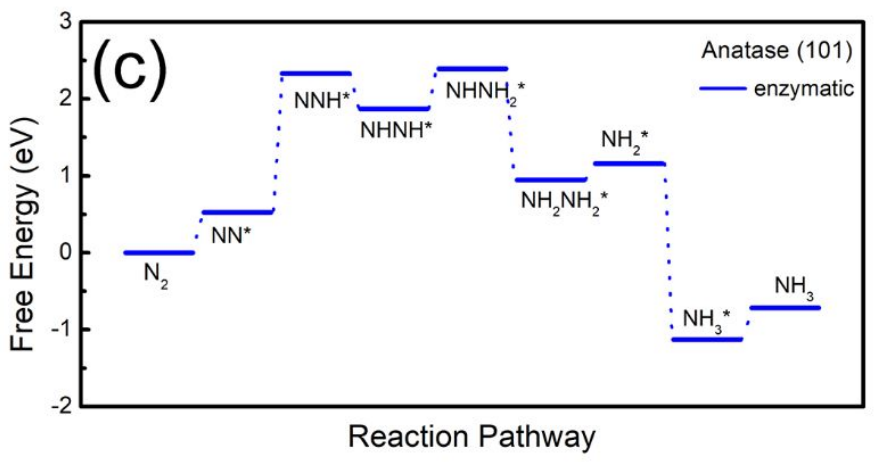

Figure S18. DFT calculated for the energetics of the NRR steps on the (101) facets of anatase $\mathrm{TiO}_{2}$ through the (a) distal, (b) mixed and (c) enzymatic mechanisms.

Figure S18 shows the DFT calculated for the energetics of the NRR steps on the (101) facets of anatase $\mathrm{TiO}_{2}$ through the distal, mixed and enzymatic mechanisms. It is obvious that the rate-limiting step in all three mechanisms is the protonation of $\mathrm{NN}^{*}$ to form $\mathrm{NNH}^{*}$ species. Nevertheless, the enzymatic mechanism is still preferred due to its much lower exothermicity from $* \mathrm{NH}_{2} \mathrm{NH}_{2}$ to $* \mathrm{NH}_{2}$. 

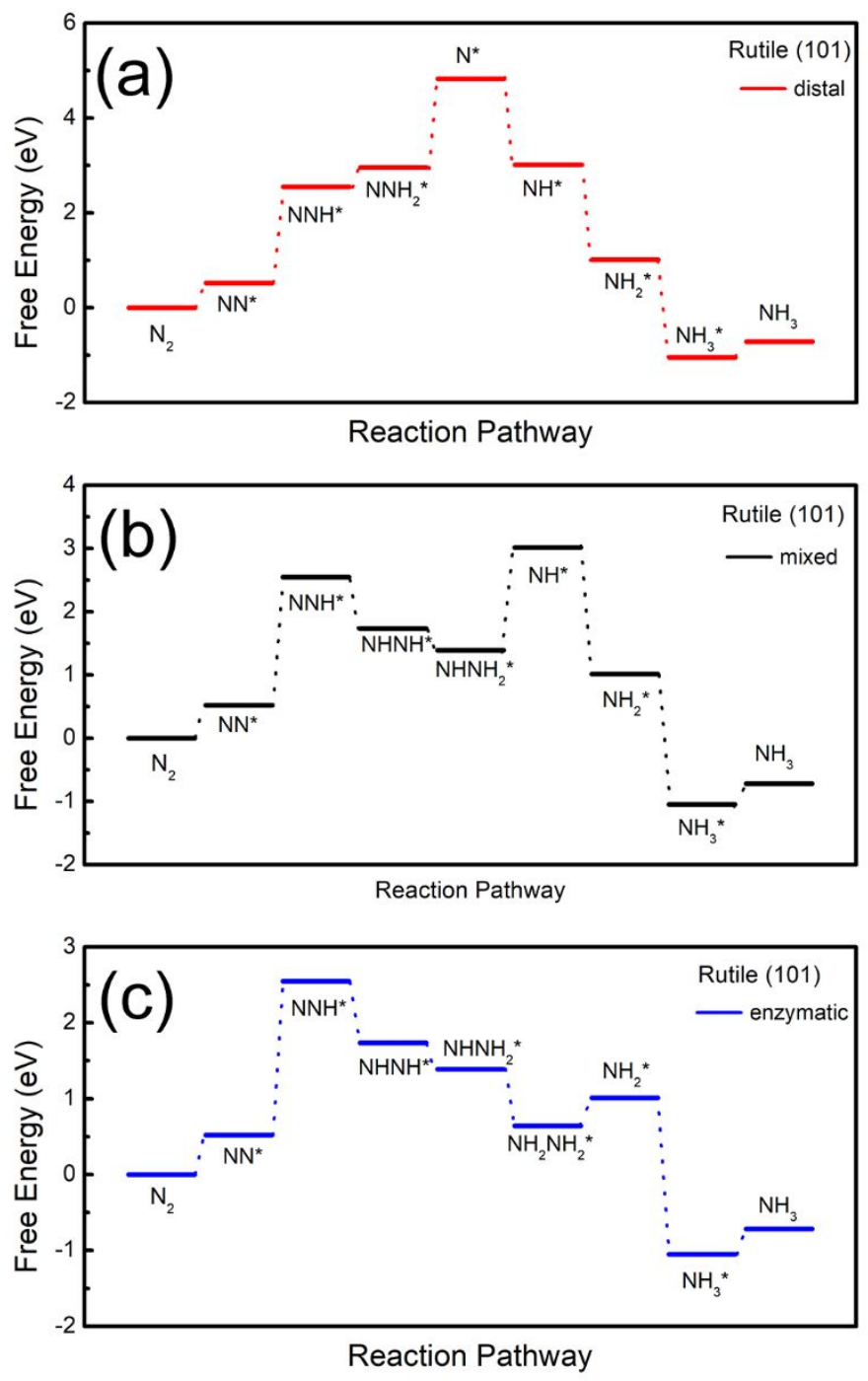

Figure S19. DFT calculated for the energetics of the NRR steps on the (101) facets of rutile $\mathrm{TiO}_{2}$ through the (a) distal, (b) mixed and (c) enzymatic mechanisms.

Figure S19 shows the DFT calculated for the energetics of the NRR steps on the (101) facets of rutile $\mathrm{TiO}_{2}$ through the distal, mixed and enzymatic mechanisms, indicating that the enzymatic mechanism is still preferred due to its much lower exothermicity from $* \mathrm{NH}_{2} \mathrm{NH}_{2}$ to $* \mathrm{NH}_{2}$. 

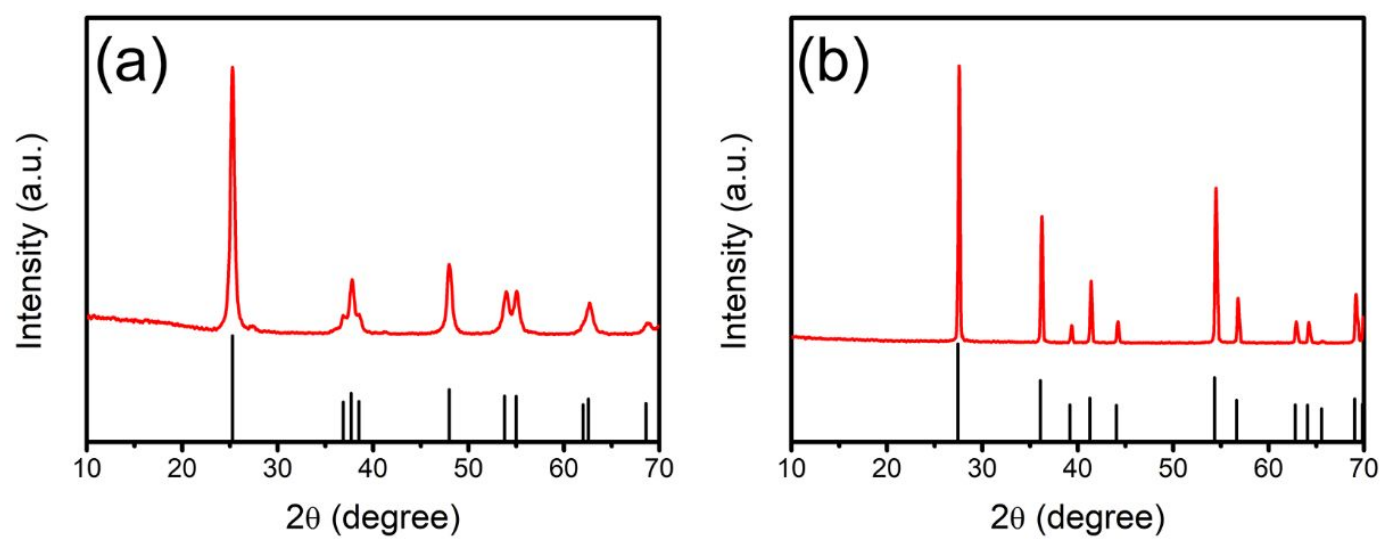

Figure S20. XRD patterns of (a) pure anatase $\mathrm{TiO}_{2}$ and (b) pure rutile $\mathrm{TiO}_{2}$.

Figure S20 shows the XRD patterns of anatase $\mathrm{TiO}_{2}$ and rutile $\mathrm{TiO}_{2}$. The purchased anatase $\mathrm{TiO}_{2}$ powders show classic peaks of anatase $\mathrm{TiO}_{2}$ phase, and the heat-treated powders exhibit classic peaks of rutile $\mathrm{TiO}_{2}$. Both powders have high crystallinity. 


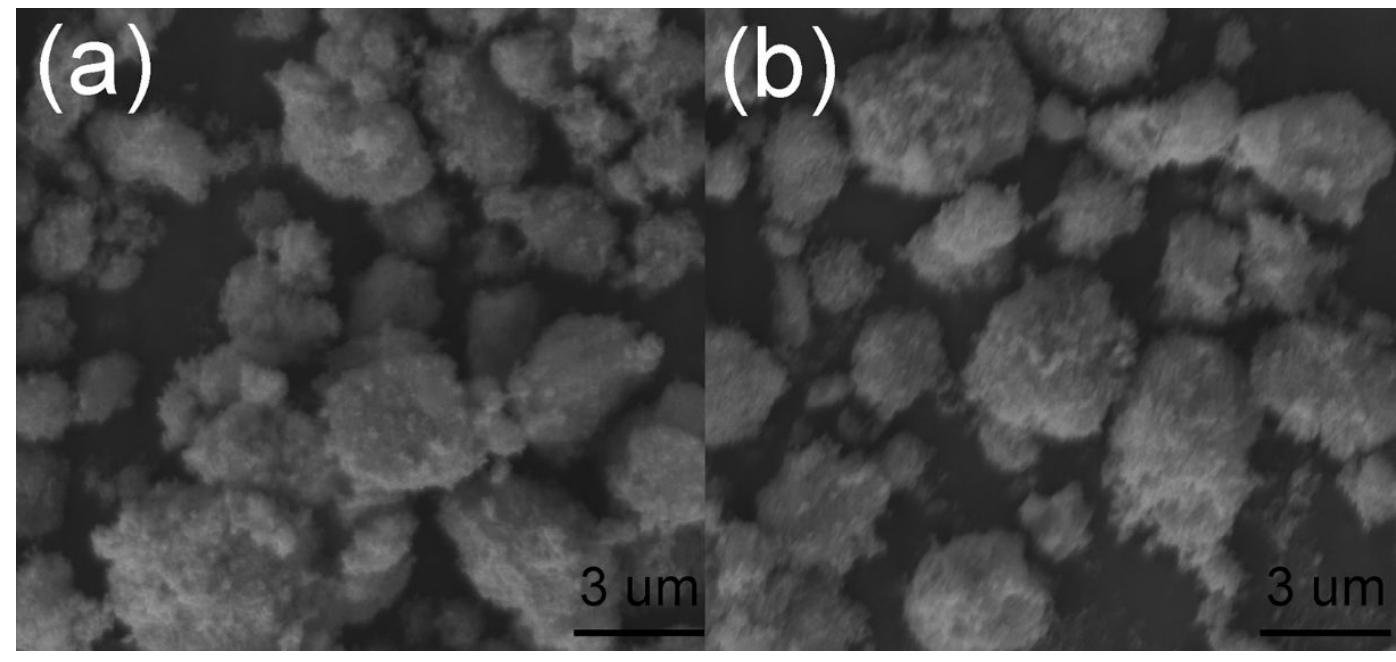

Figure S21. SEM images of the (a) anatase $\mathrm{TiO}_{2}$ and (b) rutile $\mathrm{TiO}_{2}$.

Figure $\mathrm{S} 21$ shows the SEM imagines of pure anatase $\mathrm{TiO}_{2}$ and rutile $\mathrm{TiO}_{2}$. The pure anatase and rutile $\mathrm{TiO}_{2}$ (heat treated anatase $\mathrm{TiO}_{2}$ ) show similar morphology and particle size. 

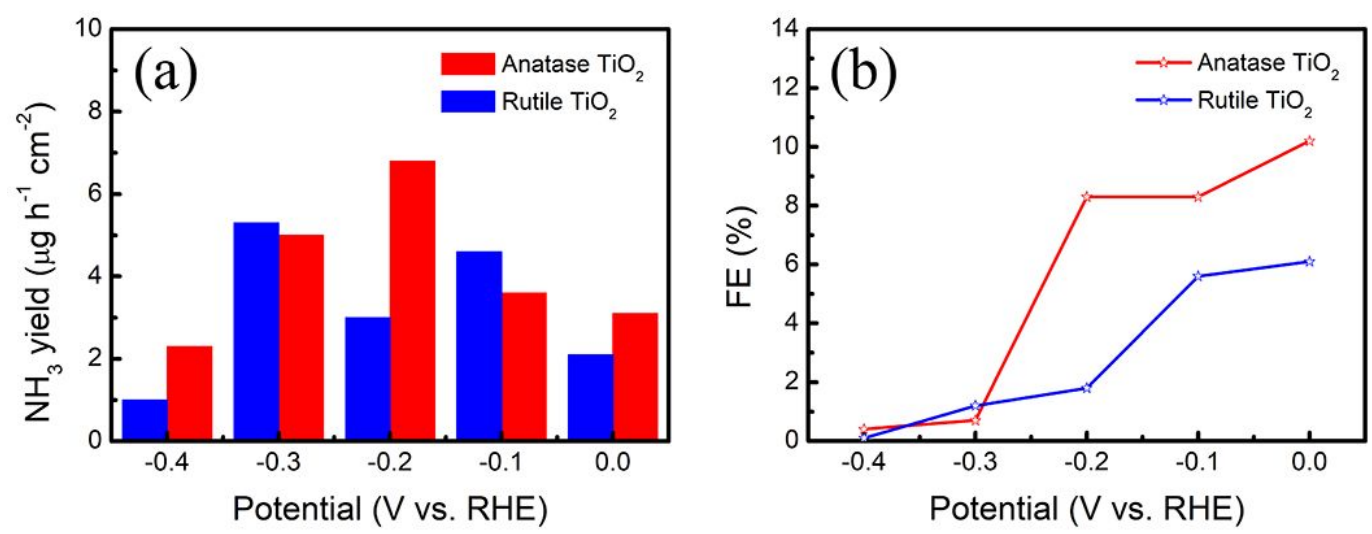

Figure $\mathbf{S 2 2}$. $\mathrm{NH}_{3}$ yields and $\mathrm{FE}$ for pure anatase $\mathrm{TiO}_{2}$ and pure rutile $\mathrm{TiO}_{2}$ at series of potentials.

Figure S22 shows the $\mathrm{NH}_{3}$ yield and FE for anatase and rutile $\mathrm{TiO}_{2}$ at series of potentials. The $\mathrm{NH}_{3}$ yield of anatase $\mathrm{TiO}_{2}$ increases with decreasing potential from $0 \mathrm{~V}$ to $-0.2 \mathrm{~V}$, but decreases with further decreased potential value till $-0.4 \mathrm{~V}$. This gives rise to a maximal $\mathrm{NH}_{3}$ yield of $6.8 \mu \mathrm{g}+\mathrm{h}^{-1}+\mathrm{cm}^{-2}$ at potential of $-0.2 \mathrm{~V}$. The maximal $\mathrm{NH}_{3}$ yield of rutile $\mathrm{TiO}_{2}$, however, is $5.6 \mu \mathrm{g}+\mathrm{h}^{-1}+\mathrm{cm}^{-2}$ at potential of $-0.3 \mathrm{~V}$. The $\mathrm{FE}$ of anatase $\mathrm{TiO}_{2}$ and rutile $\mathrm{TiO}_{2}$ decreases with decreasing potential from $0 \mathrm{~V}$ to $-0.4 \mathrm{~V}$, and the $\mathrm{FE}$ of anatase has high $\mathrm{FE}$ than rutile at most potential. It is clear that anatase $\mathrm{TiO}_{2}$ has higher $\mathrm{NH}_{3}$ yield and $\mathrm{FE}$ than rutile $\mathrm{TiO}_{2}$, indicating that the pure anatase $\mathrm{TiO}_{2}$ powders exhibit much better NRR activity than rutile $\mathrm{TiO}_{2}$ powders. 
Table 1. Comparison of the electrocatalytic NRR performance of annealed MXene with other aqueous-based NRR electrocatalysts at room temperature.

\begin{tabular}{|c|c|c|c|c|}
\hline Catalyst & Electrolyte & $\begin{array}{c}\mathrm{NH}_{3} \text { yield } \\
\left(\mu \mathrm{g} /\left(\mathrm{h}+\mathrm{cm}^{2}\right)\right)\end{array}$ & FE $(\%)$ & Reference \\
\hline $\begin{array}{l}\text { Anatase } \\
\mathrm{TiO}_{2} / \mathrm{C}\end{array}$ & $0.1 \mathrm{M} \mathrm{Na}_{2} \mathrm{SO}_{4}$ & 14.0 & 13.3 & This work \\
\hline $\mathrm{TiO}_{2}-\mathrm{rGO}$ & $0.1 \mathrm{M} \mathrm{Na}_{2} \mathrm{SO}_{4}$ & 6.05 & 3.3 & 1 \\
\hline $\mathrm{TiO}_{2} / \mathrm{Ti}$ & $0.1 \mathrm{M} \mathrm{Na}_{2} \mathrm{SO}_{4}$ & 5.6 & 2.5 & 2 \\
\hline$\beta-\mathrm{FeOOH}$ & $0.5 \mathrm{M} \mathrm{LiClO}_{4}$ & 4.67 & 6.7 & 3 \\
\hline $\mathrm{MoS}_{2}$ & $0.1 \mathrm{M} \mathrm{Na}_{2} \mathrm{SO}_{4}$ & 4.94 & 1.17 & 4 \\
\hline Hollow Au & $0.5 \mathrm{M} \mathrm{LiClO}_{4}$ & 3.74 & 35.9 & 5 \\
\hline $\begin{array}{c}\text { Polymeric } \\
\text { Carbon Nitride }\end{array}$ & $0.1 \mathrm{M} \mathrm{HCl}$ & 8.09 & 11.59 & 6 \\
\hline $\begin{array}{c}\mathrm{MoO}_{3} \\
\text { nanosheet }\end{array}$ & $0.1 \mathrm{M} \mathrm{HCl}$ & 29.4 & 1.9 & 7 \\
\hline $\mathrm{Fe}_{2} \mathrm{O}_{3}-\mathrm{CNT}$ & $\mathrm{KHCO}_{3}$ & 0.22 & 0.15 & 8 \\
\hline $\mathrm{Fe}_{3} \mathrm{O}_{4}$ & $0.1 \mathrm{M} \mathrm{Na}_{2} \mathrm{SO}_{4}$ & 3.43 & 2.6 & 9 \\
\hline Ag nanosheets & $0.1 \mathrm{M} \mathrm{HCl}$ & 2.83 & 4.8 & 10 \\
\hline
\end{tabular}

\section{Reference:}

1. Zhang, X. X.; Liu Q.; Shi X. F.; Asiri A. M.; Luo Y. L.; Sun X. P.; Li T. S. TiO nanoparticles-reduced graphene oxide hybrid: an efficient and durable electrocatalyst toward artificial $\mathrm{N}_{2}$ fixation to $\mathrm{NH}_{3}$ under ambient conditions. $J$. 
Mater. Chem. A 2018, 6, 17303-17306.

2. Zhang R.; Xiang R.; Shi X. F.; Xie F. Y.; Zheng B. Z.; Guo X. D.; Sun X. P. Enabling Effective Electrocatalytic $\mathrm{N}_{2}$ Conversion to $\mathrm{NH}_{3}$ by the $\mathrm{TiO}_{2}$ Nanosheets Array under Ambient Conditions. ACS Appl. Mater. Interfaces 2018, 10, $28251-28255$.

3. Zhu X. J.; Liu Z. C.; Liu Q.; Luo Y. L.; Shi X. F.; Asiri A. M.; Wu Y. P.; Sun X. P. Efficient and Durable $\mathrm{N}_{2}$ Reduction Electrocatalysis under Ambient Conditions: $\beta$ FeOOH Nanorods as a Non-Noble-Metal Catalyst. Chem. Commun., 2018, 54, $11332-11335$.

4. Zhang L.; Ji X. Q.; Ren X.; Ma Y. J.; Shi X. F.; Tian Z. Q.; Asiri A. M.; Chen L.; Tang B.; Sun X. P. Electrochemical Ammonia Synthesis via Nitrogen Reduction Reaction on a $\mathrm{MoS}_{2}$ Catalyst: Theoretical and Experimental Studies. Adv. Mater. 2018, 30, 1800191.

5. Nazemi M.; EI-Sayed M. A. Electrochemical Synthesis of Ammonia from $\mathrm{N}_{2}$ and $\mathrm{H}_{2} \mathrm{O}$ under Ambient Conditions Using Pore-Size-Controlled Hollow Gold Nanocatalysts with Tunable Plasmonic Properties. J. Phys. Chem. Lett. 2018, 9, $5160-5166$.

6. Lv C. D.; Qian Y. M.; Yan C. S.; Ding Y.; Chen G.; Yu G. H. Defect Engineering Metal-Free Polymeric Carbon Nitride Electrocatalyst for Effective Nitrogen Fixation under Ambient Conditions. Angew. Chem. Int. Ed. 2018, 57, 10246 -10250.

7. Han, J.; Ji, X.; Ren, X.; Cui, G.; Li, L.; Xie, F.; Wang, H.; Li, B.; Sun, X. MoO3 Nanosheet for Efficient Electrocatalytic $\mathrm{N}_{2}$ Fixation to NH3. J. Mater. Chem. A 
2018, 6, 12974-12977.

8. Chen, S.; Perathoner, S.; Ampelli, C.; Mebrahtu, C.; Su, D.; Centi, G. Electrocatalytic Synthesis of Ammonia at Room Temperature and Atmospheric Pressure from Water and Nitrogen on a Carbon-Nanotube-Based Electrocatalyst. Angew. Chem. Int. Ed. 2017, 56, 2699-2703.

9. Liu Q.; Zhang X. X.; Zhang B.; Luo Y. L.; Cui G. W.; Xie F. Y.; Sun X. P. Ambient $\mathrm{N}_{2}$ fixation to $\mathrm{NH}_{3}$ electrocatalyzed by a spinel $\mathrm{Fe}_{3} \mathrm{O}_{4}$ nanorod. Nanoscale, 2018, $10,14386-14389$.

10. Huang H. H.; Xia L.; Shi X. F.; Asiri A. M.; Sun X. P. Ag nanosheets for efficient electrocatalytic $\mathrm{N}_{2}$ fixation to $\mathrm{NH}_{3}$ under ambient conditions. Chem. Commun., 2018, 54, 11427-11430. 